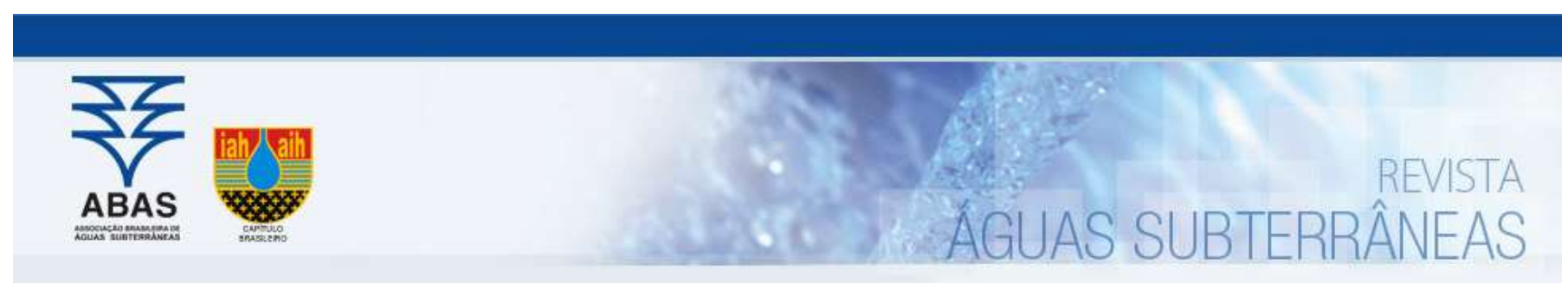

Artigos

\title{
Análise dos fluxos nos aquíferos cárstico-fissurais da região da APA Carste de Lagoa Santa, MG
}

\section{Analysis of karst-fractured aquifers flows of the Lagoa Santa Karst EPA region, MG}

\author{
Carolina Gomes Ribeiro1; Leila Nunes Menegasse Velásquez²; Rodrigo Sérgio de Paula1; Cecília Gouvêa Meireles³; Nilo Henrique Balzani \\ Lopes4; Rolando Esteban Clavijo Arcos4; Diógenes Guilherme Pampolini Amaral1 ${ }^{\bowtie}$
}

1 Programa de Pós-graduação em Geologia do Instituto de Geociências da Universidade Federal de Minas Gerais (IGC-UFMG)

2 Departamento de Geologia do Instituto de Geociências da Universidade Federal de Minas Gerais (IGC-UFMG)

3 Pesquisadora Independente

4 Programa de Pós-graduação em Ciência e Tecnologia das Radiações, Minerais e Materiais do Centro de Desenvolvimento da Tecnologia Nuclear (CDTN

5 Programa de Pós-graduação em Geociências da Universidade Federal de Pernambuco (UFPE)

$\triangle$ cgrcarol@gmail.com, menegase@yahoo.com.br, rodrigo.spdm@yahoo.com.br, ceciliagmeireles@gmail.com, balzaniloh@gmail.com, esteban_clavijoarcos@hotmail.com, diogenesgeologo@gmail.com

Resumo

Palavras-chave:

APA Carste de Lagoa Santa. Aquíferos cárstico-fissurais. Fraturas.

Paleocondutos.

A área de estudos, que engloba a Área de Proteção Ambiental (APA) Carste de Lagoa Santa, se estende por 504 km². Nesta região, ocorrem os metacalcários da Formação Sete Lagoas, composta pelos membros Pedro Leopoldo e Lagoa Santa, os quais acomodam os aquíferos cárstico-fissurais. 0 método de estudo envolveu o levantamento de estruturas rúpteis e de dissolução cárstica em uma malha de $9.000 \mathrm{~m}^{2}$, escala 1:300.000, com a finalidade de analisá-las e associá-las com as direções de cavernas e com direções de fluxos da água subterrânea comprovadas por testes de traçadores corantes (E-W, NE e SE), de sentido oriental. Por toda a área, a preponderância sistemática de cavernas e paleocondutos reliquiares na direção N70-90W, com caimento suave para leste, indica que esses paleocondutos resultam da dissolução ao longo da interseção das fraturas $E$ W, de alto ângulo, com o plano de acamamento suave, de direção NNW. Fraturas de alto ângulo de direção NE e SE também são frequentes, contudo, são raras as exposições dos paleocondutos e cavernas correlatos. Em contrapartida, embora as cavernas N-S se destaquem como mais persistentes e alongadas, assim como as E-W, não se observaram fluxos de água naquela direção (N-S). Os resultados demonstram que os parâmetros estruturais primordiais, as fraturas de alto ângulo e o acamamento, condicionam os fluxos subsuperficiais em condutos de cavernas ainda ativos no sentido oriental. No entanto, não se descarta a possibilidade de ocorrerem circulações profundas em segmentos N-S não observáveis nas zonas superiores.

Abstract

Keywords:

The study area, which encompasses the Environmental Protection Area (EPA) of the Lagoa Santa Karst, has an extension of 504 $\mathrm{km}^{2}$. In this region, metalimestones from the Sete Lagoas Formation occur, composed by Pedro Leopoldo and Lagoa Santa members, which accommodate the karst-fractured aquifers. The study method involved the collection of brittle and of karst dissolution structural measurements in a 9,000 $\mathrm{m}^{2}$ mesh, 1:300,000 scale, with the purpose of analyzing and associating them with cave directions and with groundwater flow directions toward east proven by dye tracer tests (E-W, NE and SE). Throughout the area, the systematic preponderance of caves and reliquary paleoconduits in N70-90W direction, with smooth plundge to east, indicates these paleoconduits result from dissolution along the intersection of high angle E-W fractures with smooth NNW bedding. High angle fractures, with NE and SE directions, are also frequent, although the exposure of their correlated paleoconduits and caves are rare. Nevertheless, even though N-S caves stand out as more persistent and elongated as well as E-W ones, groundwater flows were not observed in N-S direction. Results show that primordial structural parameters (high angle fractures and bedding planes) condition the underground flows in still active cave conduits toward east. However, there is a possibility of deep circulations in non-observable N-S segments occurring in the upper zones.

DOI: http:/dx.doi.org/10.14295/ras.v33i1.29148

\section{INTRODUÇÃO}

Localizada a norte da Região Metropolitana de Belo Horizonte (RMBH), MG, a Área de Proteção Ambiental (APA) Carste de Lagoa Santa perfaz cerca de $80 \%$ da área foco de estudos, cujas princi- pais atividades econômicas são a mineração de calcário, seguida da agropecuária. A região foi alvo de pesquisas geomorfológicas, arqueológicas e paleontológicas desde a primeira metade do sécuIo XIX, com o pioneirismo do naturalista dinamarquês Peter Lund (VIANA; KOHLER; TAVARES, 1998; BERBERT-BORN, 2002; DA- 
GLORIA; NEVES; HUBBE, 2017), o que evidencia o elevado valor histórico, cultural e científico da unidade de conservação.

A intrincada rede local de fraturas, condutos de dissolução e sumidouros, que compõe os aquíferos cársticos-fissurais dessa região, promove uma circulação de água predominantemente subterrânea. A investigação dos fluxos demanda estudos da anisotropia das rochas a partir das estruturas rúpteis, de dissolução e sedimentares. Portanto, este estudo foi realizado visando a identificar e caracterizar em campo as estruturas de interesse e associá-las entre si e com as direções de fluxo levantadas em estudos préexistentes. Como esses aquíferos possuem grande potencial hídrico e alta vulnerabilidade quali-quantitativa, seu monitoramento e gestão são imprescindiveis a fim de garantir o abastecimento futu- ro dos vários municípios que dependem desse recurso.

\section{2. ÁREA DE ESTUDO}

\subsection{Localização e Fisiografia}

A área estudada está a cerca de $35 \mathrm{~km}$ a norte de BH (Figura 1); possui extensão de $504,9 \mathrm{~km}^{2}$; e envolve parcial ou integralmente os municípios da RMBH: Vespasiano, Lagoa Santa, Confins, Pedro Leopoldo, Matozinhos, Prudente de Morais e Funilândia. A área extrapola a APA Carste a noroeste e a oeste, com os demais limites coincidentes, e é delimitada a leste pelo Rio das Velhas, a oeste e sul pelo Ribeirão da Mata e a norte por divisores de águas.

Figura 1 - Localização da área de estudos

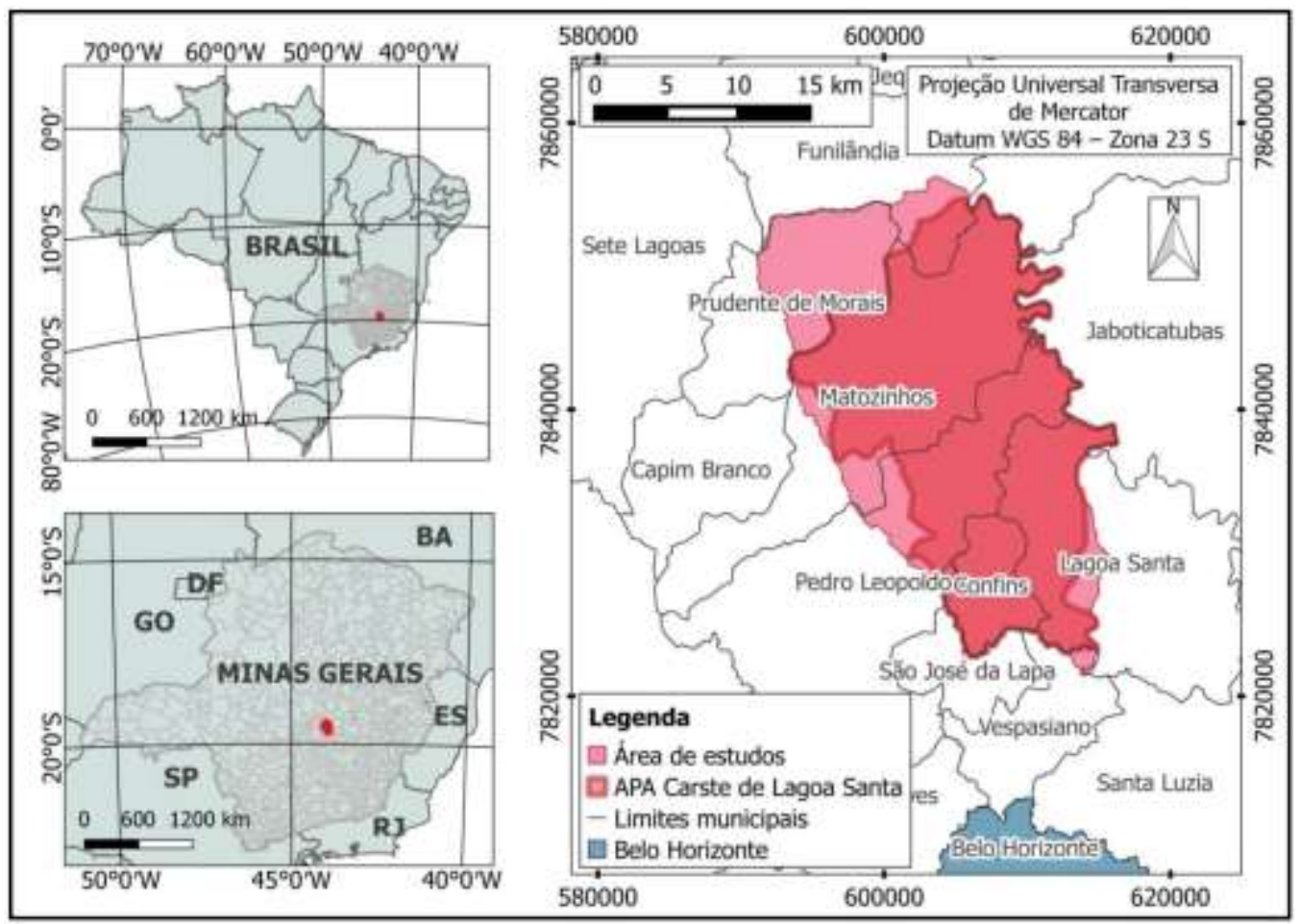

O Rio das Velhas, maior afluente em extensão da Bacia Hidrográfica do Rio São Francisco, é o nível de base regional da área e um de seus principais afluentes, a oeste, é o Ribeirão da Mata. Viana, Kohler e Tavares (1998) definiram seis sub-bacias hidrográficas na área de estudo, as quais drenam os córregos do Jaque, Samambaia, Palmeira, Jaguara, Gordura e Flor. A precipitação média anual é de 1.286,5mm (VIANA; KOHLER; TAVARES, 1998).

O relevo ruiniforme é caracterizado por maciços de rochas carbonáticas aflorantes intensamente fraturadas, sumidouros, dolinas, surgências, ressurgências, vales cegos e cavernas.

\subsection{Contexto Tectono-Estrutural e Geológico}

A área está na Bacia Sedimentar do São Francisco, composta principalmente por rochas sedimentares clásticas e carbonáticas neoproterozoicas do Supergrupo São Francisco. A Bacia do São Francisco foi dividida nos compartimentos tectono-estruturais Ocidental, Central e Oriental. Neste último, onde está a área estudada, as rochas foram afetadas pelos movimentos orogênicos da Faixa Araçuaí, vergentes para oeste, com ausente a baixo grau de metamorfismo crescente para leste, assim como a magnitude da deformação (ALKMIM; MARTINS-NETO, 2001).

O Complexo Gnáissico-granítico Migmatítico (Figura 2) é o embasamento nos contextos regional e local, e seu contato com as unidades sobrepostas do Grupo (Gr.) Bambuí é brusco, tectônico e por discordância angular (RIBEIRO et al., 2003). Sua exposição na área limita-se a calha do Ribeirão da Mata.

Acima do embasamento, a base do Gr. Bambuí compreende apenas as formações Sete Lagoas (carbonática) e Serra de Santa Helena (pelítica). A Formação (Fm.) Sete Lagoas é subdividida nos membros, da base para o topo, Pedro Leopoldo e Lagoa Santa (VIANA; KOHLER; TAVARES, 1998; RIBEIRO et al., 2003). Os aquíferos cárstico-fissurais, foco deste trabalho, estão contidos nessa formação, a qual aflora em 65\% da área de estudos.

O Membro (Mb.) Pedro Leopoldo (Figura 2) assenta-se sobre o embasamento geralmente por falha de descolamento (RIBEIRO et al., 2003). É constituído por metacalcários calcíticos cristalinos muito finos a médios, impuros, com lâminas ricas em filossilicatos, 
concordantes com o acamamento e a foliação. Essa impureza implica na formação de feições cársticas irregulares, chegando a apresentar porções não carstificadas a leste da área de estudos norte de Lagoa Santa, leste de Pedro Leopoldo, leste de Matozinhos e sul de Funilândia.

O Mb. Lagoa Santa (Figura 2) é a unidade de maior extensão aflorante, e sobrepõe-se ao Mb. Pedro Leopoldo geralmente em contato brusco, mediante falha de descolamento (RIBEIRO et al., 2003). É caracterizado por metacalcários calcíticos cristalinos puros, granulação média a grossa, e lâminas muito finas de calcita inter- caladas seguindo a orientação do acamamento.

A Fm. Serra de Santa Helena (Figura 2) encontra-se comumente em contato tectônico sobre a Fm. Sete Lagoas (RIBEIRO et al., 2003), e é constituída essencialmente por folhelho síltico bastante intemperizado.

As Coberturas Cenozoicas (Figura 2) abrangem as Coberturas Detrito-lateríticas e as Coberturas Aluvionares (RIBEIRO et al., 2003).

Figura 2 - Mapa Geológico da área de estudos

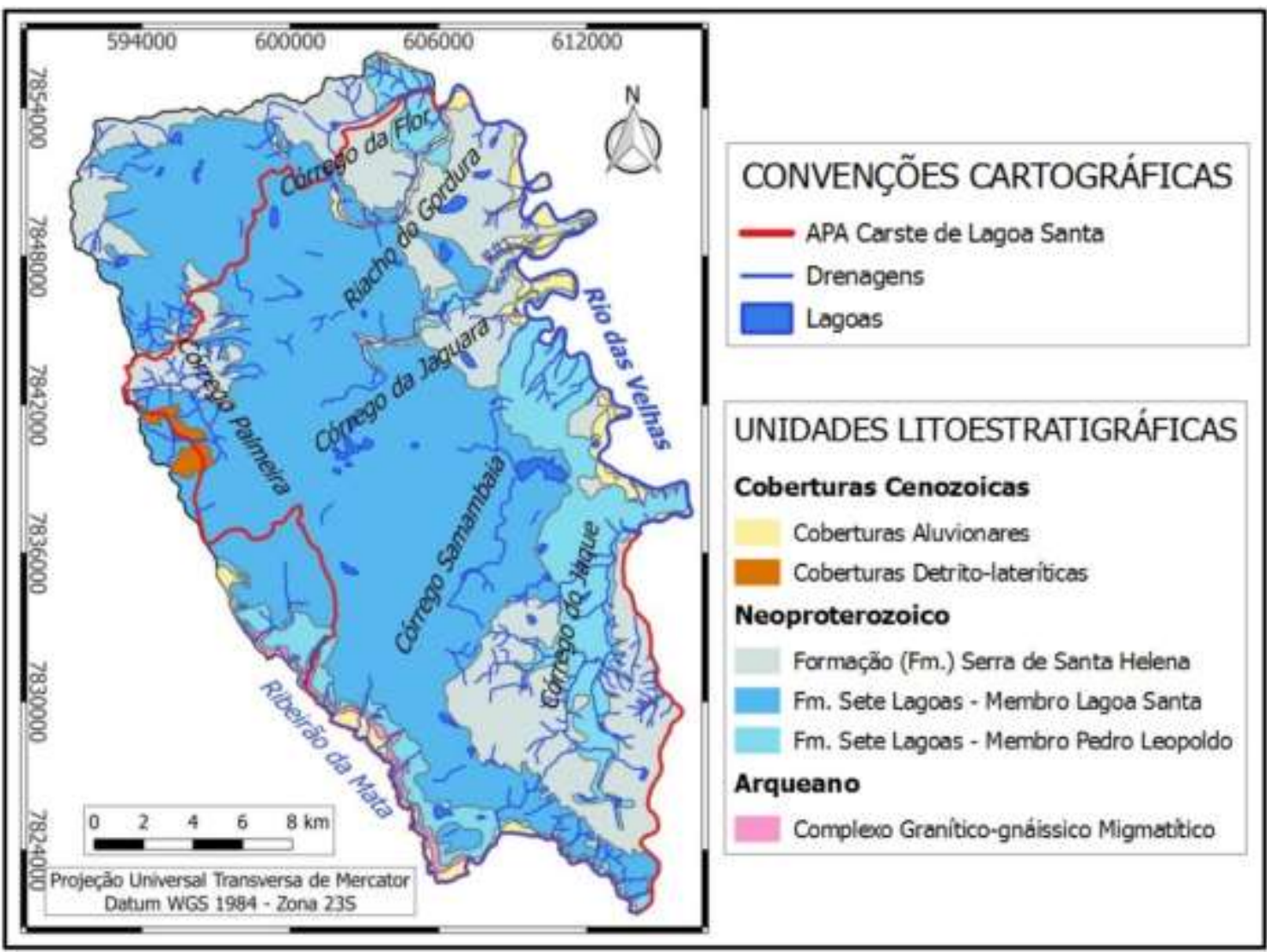

Fonte: Adaptado de Ribeiro et al.(2003)

\subsection{Contextos Espeleogenético e Espeleológico}

A atitude estrutural da rocha - geometrias planares, lineares e suas interconexões - e a relação geográfica entre a área de recarga e descarga são aspectos importantes no desenvolvimento do carste (FORD; WILLIAMS, 2007).

A água de recarga alarga os poros primários e as fraturas (secundárias), enquanto a circulação de água persistir, fazendo com que os fluxos fiquem cada vez mais organizados à medida que a estrutura se desenvolve. Quando essa dissolução desenvolve caminhos para tubulações (condutos ou cavernas), esses são chamados de porosidade terciária (FORD; WILLIAMS, 2007).

Shuster e White (1971) classificaram os sistemas de fluxos de um aquífero cárstico-fissural em "fluxo difuso", o qual ocorre no meio com predomínio do regime laminar em fraturas, e "fluxo por condutos", no qual predomina o regime turbulento. Nesse cenário, as fraturas favorecem a recarga, porém possuem menor capacidade de armazenamento e transmissividade, se comparada aos condutos.

White (2002) apontou mudanças na hidrodinâmica, cinética e no transporte de água como uma linha de divisão natural entre aquíferos fraturados e de condutos. Tais mudanças separam o processo de desenvolvimento de condutos em uma fase de protoconduto, em que não há ligação entre um ponto de entrada e saída de água, para uma fase de conduto, culminando no desenvolvimento de uma surgência a partir de uma infiltração. Segue uma repentina transição para a rápida dissolução ocasionando alargamento dos condutos e, onde estes se estendem continuamente entre entrada e saída, constitui-se um sistema de cavernas integrado. A maioria das cavernas penetráveis são porções de tais sistemas (FORD; WILLIAMS, 2007).

A maioria dos aquíferos cársticos inclui todas as combinações possíveis de estágios da evolução de drenagem, detendo cada um dos componentes de porosidade (matriz, fissural e condutos), 
porém precisam possuir um componente de conduto dominante, que forneça caminhos para o fluxo (FORD; WILLIAMS, 2007).

O termo condutos inclui os corredores de dissolução, sejam ou não do tamanho de caverna (penetrável ao homem), capazes de transmitir fluxo turbulento, e podem ser parcial ou temporariamente preenchidos por água (PALMER, 2007). Com o desenvolvimento da carstificação, o nível freático regional é gradualmente rebaixado e os condutos freáticos esvaziados (FORD; WILLIAMS, 2007).

De acordo com Berbert-Born, Horta e Dutra (1998), o Carste de Lagoa Santa guarda grande heterogeneidade na relação entre a configuração ou dinâmica hidrológica e a gênese e morfologia das cavernas. A gênese dessas estruturas pode estar associada a lagoas, ao fluxo rápido e turbulento de rios subterrâneos ou a águas intersticiais que percolam em fluxo descendente as descontinuidades da rocha (BERBERT-BORN; HORTA; DUTRA, 1998). Segundo Auler e Piló (2015), há mais de 700 cavernas no Carste de Lagoa Santa, as quais são seções curtas de sistemas bem maiores que foram expostos ou segmentados por afundamento de dolinas e abaixamento da superfície e de vales. 0 padrão de cavernas mais característico é labiríntica anastomosada (AULER; PILÓ, 2015).

\subsection{Contexto Hidrogeológico}

Segundo Auler (1994), a água nos aquíferos cárstico-fissurais da região acompanha tanto o mergulho do calcário, geralmente no sentido leste (Rio das Velhas), assim como as principais direções de fraturas, embora Auler (1994) tenha identificado algumas rotas de fluxo discordantes dessas estruturas.

Pessoa (2005) observou que o condicionamento dos processos de carstificação na região de Lagoa Santa está atrelado à interseção dos planos interestratais, geralmente N-S, com os planos das juntas e foliações tectônicas e também às faixas de contato entre fraturas conjugadas NW-SE e ENE-SSW.

Galvão, Halihan e Hirata (2015) constataram na região de Sete Lagoas, $7 \mathrm{~km}$ a NW da área, que os fluxos ocorrem predominantemente ao longo dos planos de acamamento alargados pela dissolução e, menos comumente, pelas fraturas subverticais alargadas. Esse processo de escoamento foi igualmente notado na área de estudos.

Peñaranda-Salgado (2016), na região de Sete Lagoas, identificou três conjuntos de fraturas predominantes, no total de 152 medidas: N10-20E (C1); N30-40E (C2); e N80-W a E-W (C3). Com a utilização do modelo de Worthington (2005), em que as interseções das atitudes do acamamento com as fraturas são relacionadas a direções preferenciais de desenvolvimento de condutos, obtiveram-se três direções teóricas: N2OE (L1), N40E (L2) e N80W (L3). Observou também relações de orientação da morfologia planimétrica de 6 cavernas com as direções preferenciais das fraturas C1, C2 e C3, bem como as direções L1 e L2.

Além disso, Peñaranda-Salgado (2016) observou, no Mb. Pedro Leopoldo, um teor de MgO bem maior do que no Mb. Lagoa Santa, e relacionou isso ao potencial para geração de condutos de dissolução que, por sua vez, é mais alto no Mb. Lagoa Santa. Na área de estudos, as análises geoquímicas de Vieira, Dussin e Velásquez (2018) também revelaram esse contraste entre a composição essencialmente calcítica do Mb. Lagoa Santa e diversificada do Mb. Pedro Leopoldo, com altas concentrações de Mg e de elementos típicos de sedimentos terrígenos como Al e Si.

Assim, entende-se que a carstificação no Mb. Lagoa Santa é mais desenvolvida do que a do Mb. Pedro Leopoldo, o que foi confirmado em campo. Devido às variações de composição dos dois membros observadas na literatura, esse membro assume comportamento hidrogeológico variável, podendo abrigar aquíferos cársticofissurais ou aquíferos fissurais a aquitardes. Enquanto isso, devido à alta pureza do Mb. Lagoa Santa e sua carstificação bem desenvolvida, esse membro comporta aquíferos cárstico-fissurais a cársticos de alto potencial.

Quanto aos tipos de recarga, observa-se em campo grande quantidade de feições que promovem a recarga direta, como através das fraturas de maciços rochosos e sumidouros. A recarga difusa ocorre a partir da infiltração através do solo de preenchimento, tanto acumulada dentro das dolinas, como fora delas.

\section{MATERIAIS E MÉTODOS}

Durante os meses de julho a setembro de 2016, foram visitados 90 pontos (Figura 3) onde foram descritos os afloramentos, feições dissolutivas, litologias e estruturas, e realizadas medidas da orientação dos planos de acamamento e fraturas e das lineações dos paleocondutos. Esses paleocondutos (protocondutos e condutos) são interpretados como estruturas dissolutivas pouco evoluídas, meandrantes e reliquiares formadas em zona freática a epifreática, expostas devido ao abaixamento do nível d'água na zona vadosa. Cada afloramento expõe somente segmentos desses meandros, porém o grande número de medidas (440) é considerado representativo do comportamento dessas feições.

Para se obter uma distribuição espacial das medidas estruturais a mais homogênea possivel, procurou-se visitar dois pontos por quadrículas de $3 \mathrm{~km} \times 3 \mathrm{~km}$, em escala 1:300.000 (Figura 3).

Com o propósito de analisar e associar as estruturas, essas medidas foram plotadas em estereogramas de igual área e em diagramas de rosetas, de onde foram obtidos os principais intervalos de direção e mergulho ou caimento. Essas direções preponderantes foram interpretadas e relacionadas entre si, além de comparadas com os resultados de trabalhos anteriores, o que possibilitou a discussão sobre as direções preferenciais de fluxos atuais de águas subterrâneas.

Neste método, as estruturas medidas no exocarste foram correlacionadas com as direções atuais de fluxo subterrâneo expressas no endocarste. Contudo, as condições de fluxo atuais podem não ser as mesmas durante a formação dos paleocondutos. Além disso, a formação de condutos não se relaciona necessariamente com o gradiente hidráulico, como condutos descritos em Auler (1995). Dessa forma, as interpretações subsequentes dessa correlação levaram em consideração a premissa de que as direções principais de fluxo do endocarste na atualidade não são significantemente diferentes de as direções mais frequentes impressas no exocarste.

Essa premissa é relativamente razoável, uma vez que, quando o acamamento é suave, como no presente caso, propicia a formação de condutos na direção da interseção entre o acamamento e a 
descontinuidade, de acordo com Worthington (2005). Assim, os paleocondutos possuem direção de caimento paralela à direção da interseção do acamamento com fraturas dos metacalcários em um cenário em que ambas as estruturas vertem em direção ao nível de base regional.

Figura 3 - Mapa com a distribuição do levantamento geológico na área de estudos

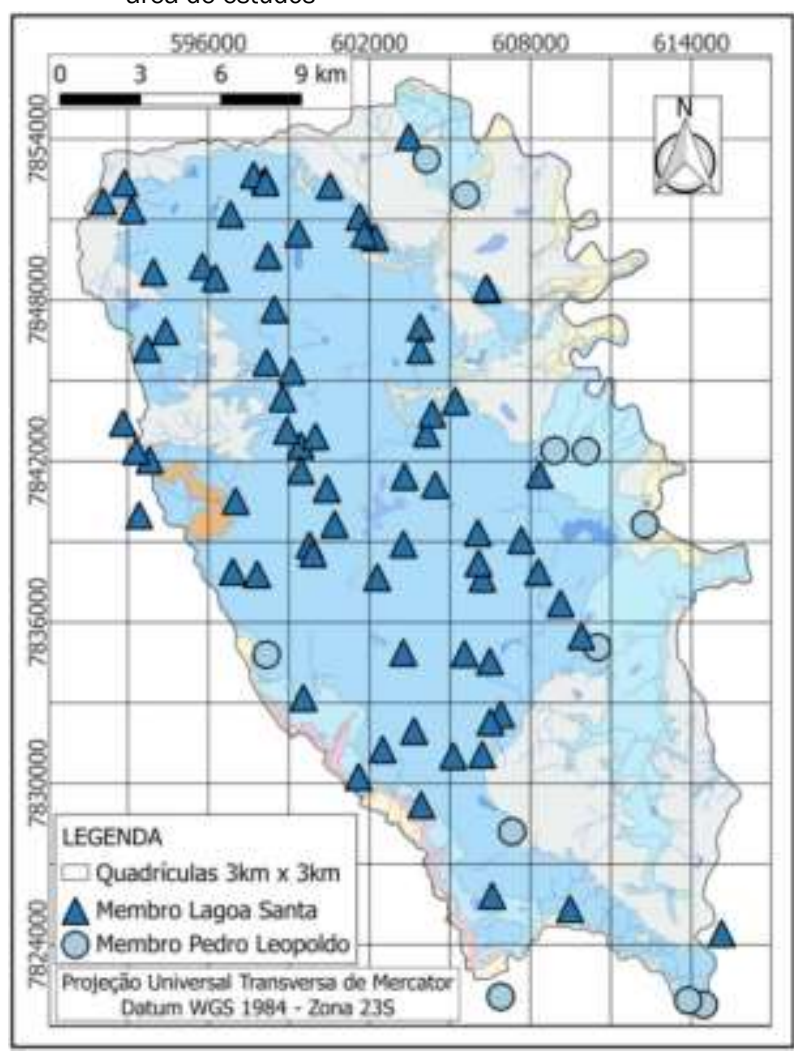

\section{RESULTADOS E DISCUSSÕES}

\subsection{Direções das estruturas: acamamento, fraturas e paleo- condutos}

Os intervalos de direções nos diagramas de rosetas de cada tipo de estrutura da Fm. Sete Lagoas estão na Tabela 1, onde, para melhor visualização da associação entre as estruturas, as direções foram agrupadas e as concordantes entre si (em até $20^{\circ}$ ) estão enumeradas de [a] a [g].

A maioria das medidas de acamamento dos metacalcários possui ângulo de mergulho $(\theta)$ menor do que $20^{\circ}$, com preponderância da direção NO-20E, grupo [a], caindo para ESE (Figuras $4 \mathrm{~A}$ e $4 \mathrm{~B})$.
Para a análise das fraturas, foram removidas as fraturas subhorizontais, sub-paralelas ao acamamento, considerando-as $\operatorname{com} \theta \leq 15^{\circ}$. Elas seriam atectônicas, isto é, resultantes do desconfinamento crustal. Além disso, essas fraturas subhorizontais representam cerca de $30 \%$ do total, o que influenciaria na análise estatística de medidas.

Devido à ampla dispersão na direção de fraturas, estas foram estabelecidas em dois grupos: $15^{\circ}<\theta<45^{\circ}$ e $\theta \geq 45^{\circ}$. No primeiro grupo $\left(15^{\circ}<\theta<45^{\circ}\right)$, predominam direções no intervalo NO40E, grupo [c] (Figuras 4C e 4D), caindo predominantemente para ESE. No segundo grupo $\left(\theta \geq 45^{\circ}\right)$, as direções estão entre N70-90E, grupo [f], e N60-90W, grupo [g], com o máximo geral em N80-90W, e outra direção constatada, NO-60E, grupo [c], possui o predomínio de planos que mergulham para E (Figura 4E e 4F). 
Tabela 1 - Direções principais das estruturas levantadas da Formação Sete Lagoas, Grupo Bambuí, obtidas por diagrama de rosetas

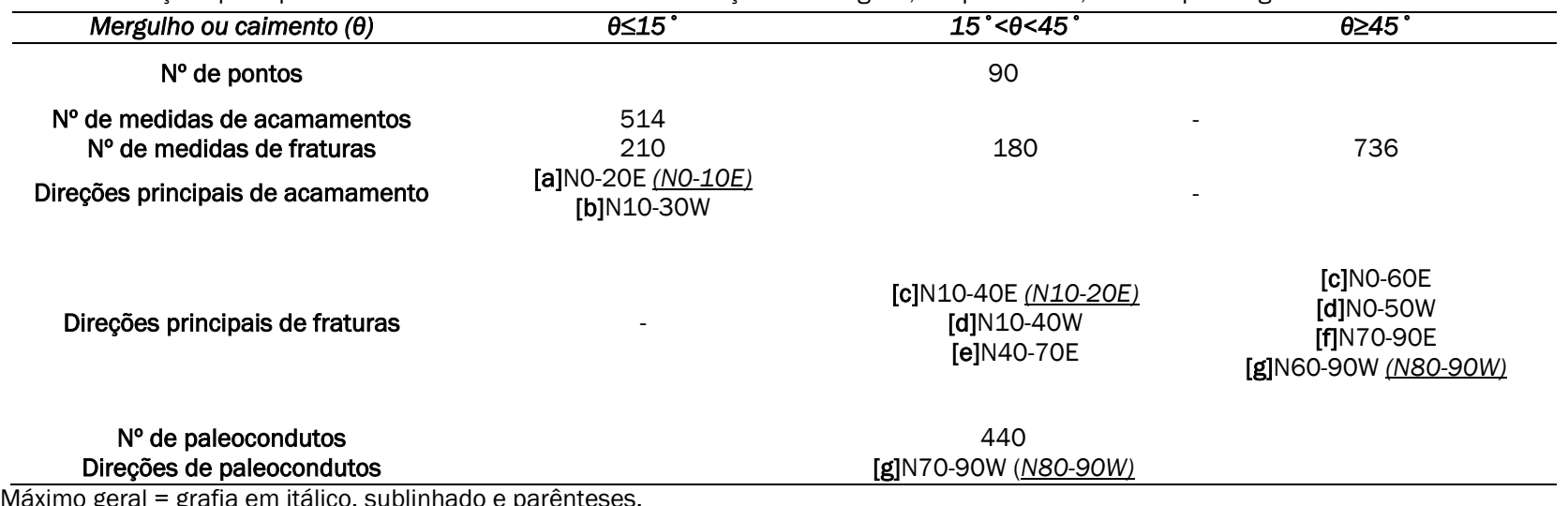

Máximo geral = grafia em itálico, sublinhado e parênteses.

[a], [b], [c], [d], [e], [f] e [g] = intervalos de direções concordantes entre si

Figura 4 - (A) Estereograma e (B) Diagrama de rosetas dos planos de acamamento da Formação Sete Lagoas. (C) Estereograma e (D) Diagrama de rosetas dos planos de fraturas da Formação Sete Lagoas com $15^{\circ}<\theta<45^{\circ}$. (E) Estereograma e (F) Diagrama de rosetas dos planos de fraturas da Formação Sete Lagoas com $\theta \geq 45^{\circ}$

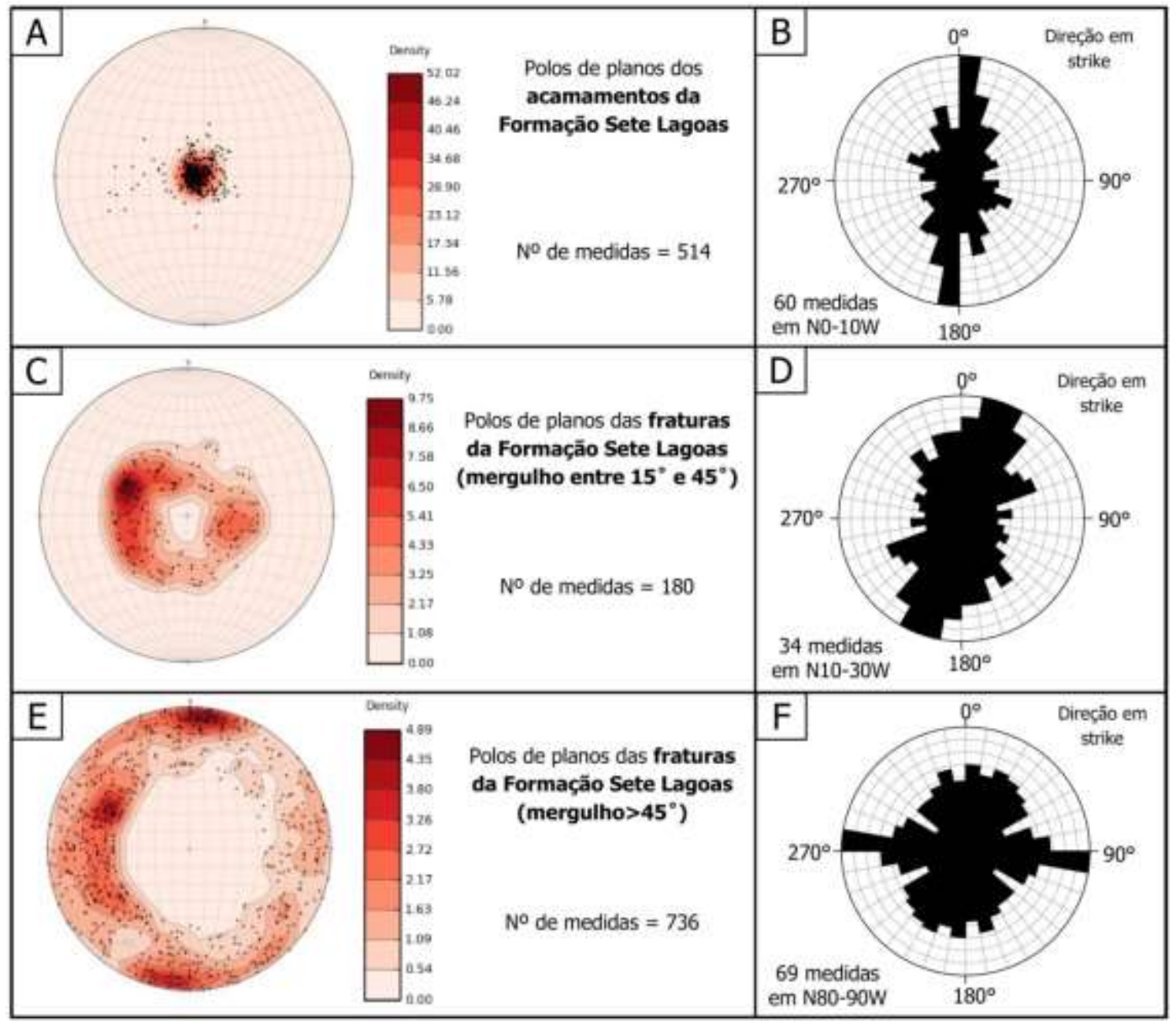

As estruturas de dissolução resultantes da carstificação são variadas e, apesar de também ocorrerem no Mb. Pedro Leopoldo, são mais evidentes em afloramentos do Mb. Lagoa Santa. Entre elas, uma das mais importantes em relação à condução de água subterrânea são os condutos de dissolução.

Uma vez que os calcários mais puros geram carstes mais desenvolvidos, suas estruturas de dissolução serão mais frequentes. Isso justifica o discrepante número de paleocondutos no Mb. Lagoa Santa (429) em relação aos escassos do Mb. Pedro Leopoldo
(21), somado também ao fato daquele membro possuir maior área aflorante do que este. No Mb. Pedro Leopoldo próximo ao limite leste, esse processo nem mesmo ocorre devido à alta densidade de lâminas filossilicáticas.

Foi observado em campo e confirmado pela análise (Figura 5A e

5B) que a maioria dos paleocondutos possui caimento subhorizontal e/ou são condicionados pelo acamamento e também por fraturas sub-horizontais, com poucos paleocondutos com 
caimento subvertical ou oblíquo. Além disso, há predomínio do intervalo de direção N70-90W, grupo [g], com 19\% das medidas na faixa N80-90W (Figura $5 \mathrm{C}$ ). Os paleocondutos tendem a merguIhar no sentido S80-90E, com dispersão de $10^{\circ}$ acima e abaixo dessa faixa (Figura 5D).
Os paleocondutos de maior frequência (N70-90W) podem ter se desenvolvido a partir da interseção dos planos das fraturas E-W e do acamamento, uma vez que eles seguem as fraturas mais frequentes dos metacalcários (N70-90W) na direção E-W e merguIham suavemente para E, ou seja, no sentido do Rio das Velhas.

Figura 5 - (A) Paleocondutos de dissolução desenvolvidos preferencialmente em um estrato do Membro Lagoa Santa (visada N60E). (B) Estereograma e (C) Diagrama de rosetas das lineações de paleocondutos da Formação Sete Lagoas. (D) Diagrama de rosetas das lineações de paleocondutos da Formação Sete Lagoas, com o peso do sentido do caimento

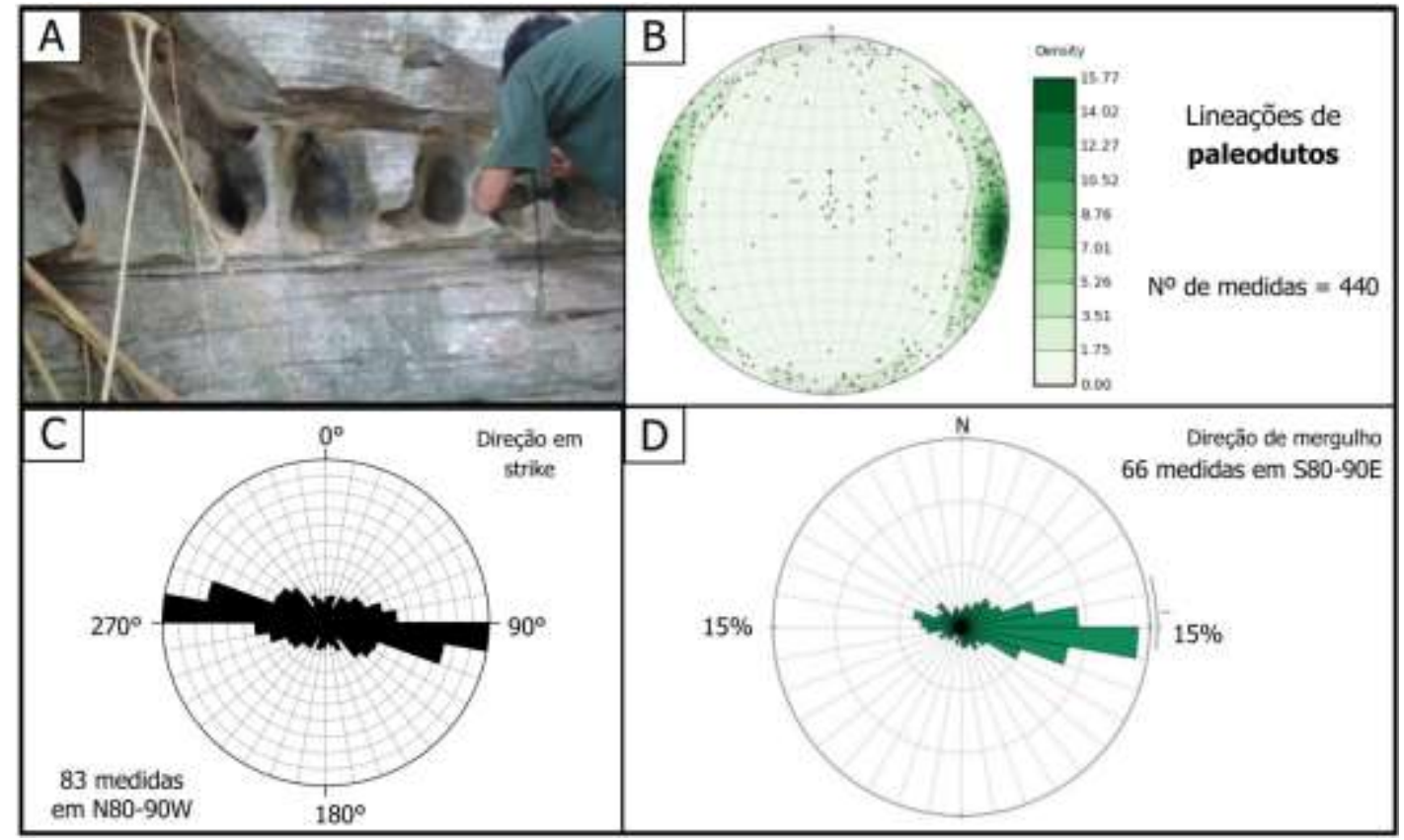

\subsection{Associações das estruturas levantadas com as de estudos} anteriores

Conforme levantamento espeleológico de Berbert-Born, Horta e Dutra (1998), as principais direções de cavernas na APA Carste de Lagoa Santa são N0-10E e N80-90W (Figuras 6A e 6B), sendo maiores e muito mais frequentes na direção N75-85E e aproximadamente N-S. A direção principal E-W dessas cavernas estaria relacionada com as principais direções de paleocondutos e fraturas dos metacalcários (N80-90W) de alto mergulho levantadas nesse estudo, e a preponderância da direção N-S teria a sua origem a partir, principalmente, de fraturas aproximadamente N-S sub-horizontais e fraturas oblíquas $\left(15^{\circ}<\theta<45^{\circ}\right)$. Constata-se, então, que duas direções de fraturas E-W e N-S são relevantes na formação de estruturas de dissolução.

Figura 6 - (A) Diagrama de rosetas de frequência de ocorrência e (B) comprimento acumulado de cavernas. Adaptado de Berbert-Born, Horta e Dutra (1998)

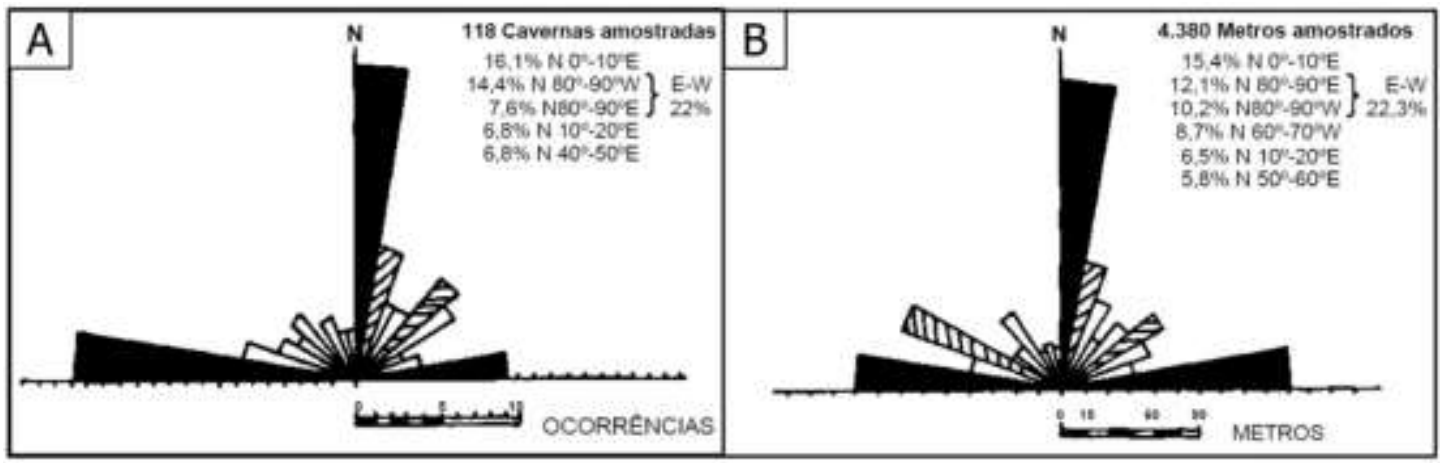

Comparando-se este estudo com a metodologia usada por Peñaranda-Salgado (2016), encontrou-se coerência em alguns dos conjuntos levantados, os quais se assemelham: C1 e C2 com [c], de fraturas NE; e C3 com [f] e [g], de fraturas ENE e WNW de alto ângulo. Encontrou-se também coerência na direção de condutos de cavernas N-S, porém não se observou as direções de condutos E-W de cavernas no trabalho em Sete Lagoas.

\subsection{Associações das estruturas com os fluxos subterrâneos}

Onde o transporte de água por meio do "fluxo por condutos" predomina, o deslocamento preferencial da água ocorreria de W para E (direção N80-90W), concordante com a direção principal das fraturas de alto ângulo $\left(\theta \geq 45^{\circ}\right)$. 0 caimento dos paleocondutos se relaciona com o caimento da interseção das fraturas de direção $\mathrm{E}$ - 
W e também com o caimento das camadas para leste e, especialmente nesta região, com as fraturas subparalelas ao acamamento (fraturas de alívio).

O acamamento constitui por si só uma descontinuidade favorável à percolação de água, destacando-se a existência de níveis pelíti$\cos$ do Mb. Pedro Leopoldo, assim como calcita das laminações de ambos os membros, que também podem favorecer a dissolução planar por influência das fraturas sub-horizontais de desconfinamento crustal. Galvão, Halihan e Hirata (2015) verificaram isso em Sete Lagoas ao identificar dois planos principais de acamamento alargados por dissolução com ampla capacidade de armazenamento aquífero.
O mapa de direções de fluxo local (Figura 7) baseou-se em oito testes com traçadores corantes de Auler (1994) e um de Velásquez et al. (inédito), que comprovaram comunicações de fluxo entre nascentes e sumidouros locais. Apesar do pequeno número de sentidos de fluxos comprovados (9) e seu baixo valor estatístico comparado às medidas estruturais, verificou-se que todos os fluxos rumam para os quadrantes NE ou SE e se agrupam em duas direções gerais de fluxo: i) leste - um fluxo com sentido ENE (seta 1 ), três fluxos com sentido ESE (setas 2, 3 e 5), dois fluxos com sentido para $E$ (setas 4 e 6); e ii) nordeste - três fluxos com sentido NE (setas 7, 8 e 9). Os azimutes desses fluxos estão na Figura 7.

Figura 7 - Mapa de direções de fluxo subterrâneo local obtidas de dados de testes de traçadores corantes de Auler (1994) e Velásquez et al. (inédito)

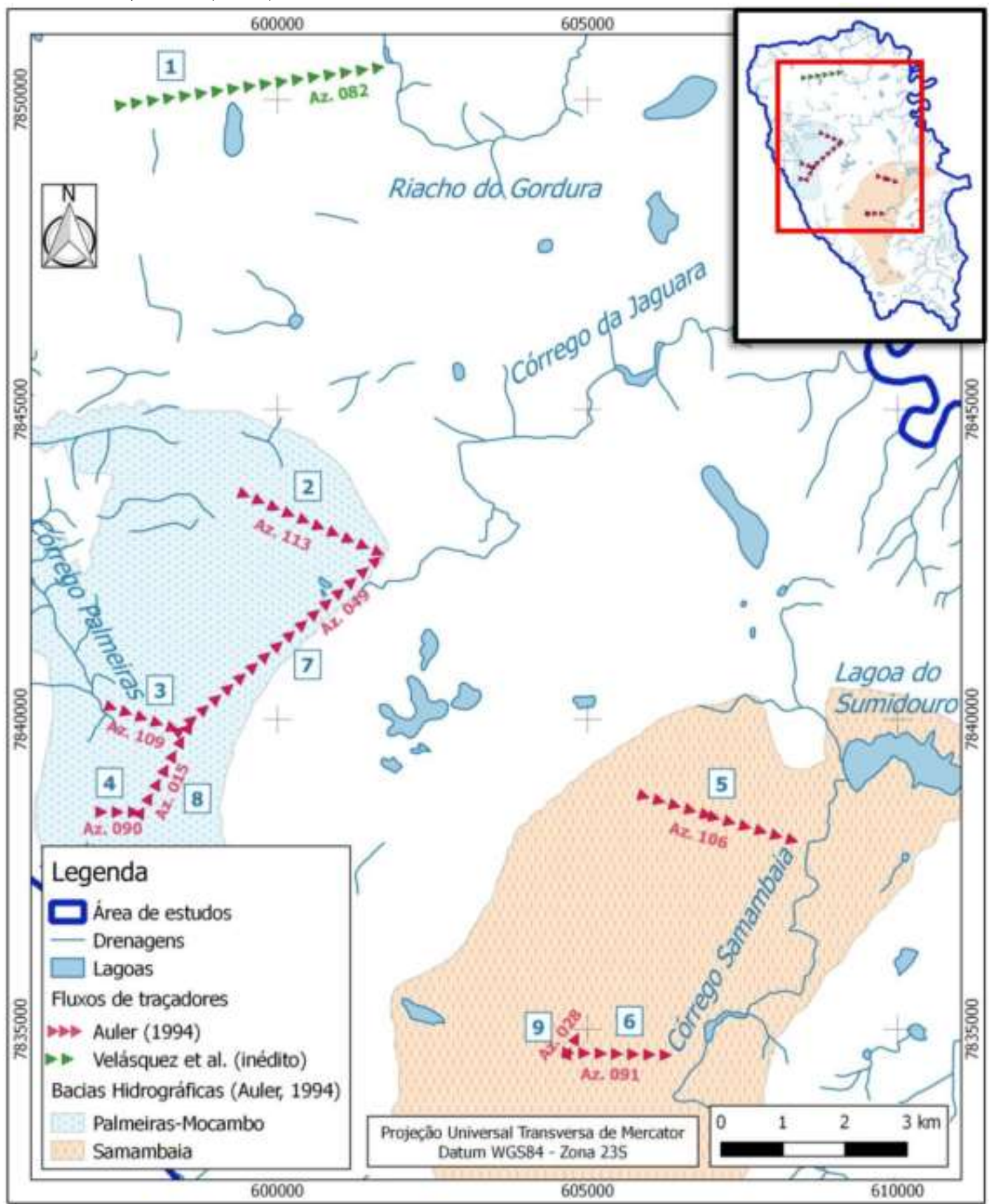


Desse modo, para esses nove resultados de fluxo, há um predomínio do sentido geral de condutos para leste. Essa direção é concordante tanto com as direções de fraturas E-W com $\theta \geq 45^{\circ}$, quanto com as direções de cavernas E-W, sugerindo uma provável associação entre essas fraturas e a carstificação no sentido para leste. O acamamento juntamente com as fraturas E-W de alto ângulo são as principais estruturas norteadoras do fluxo regional, uma vez que sua interseção dá origem à principal direção de condutos da área, que orientam a água em direção ao nível de base regional, o Rio das Velhas.

As outras direções de fluxo (NE-SW) constatadas seriam representativas de condutos resultantes da dissolução do encontro do acamamento com fraturas NE-SW com $15^{\circ}<\theta<45^{\circ}$.

Embora a direção N-S de cavernas seja marcante, ela não foi observada nos nove resultados de traçadores, cujos azimutes variam de 015 a 113. Sabe-se que as direções encontradas pelos traçadores refletem condições de fluxo atuais, enquanto os paleocondutos foram formados em condições de fluxo pretéritas. Além disso, conforme Auler (1995), na região de Lagoa Santa, os condutos N-S podem ter se desenvolvido em condições distintas, onde fraturas perpendiculares à direção de fluxo foram alargadas durante eventos de dissolução provocados por inundação em lagoas, desenvolvendo cavernas labirínticas. Entretanto, Berbert-Born, Horta e Dutra (1998) encontraram resultados expressivos de comprimento acumulado para as cavernas $\mathrm{N}-\mathrm{S}$, o que sugere que essas estruturas, além de numerosas, são bem desenvolvidas nessa direção. Isso poderia sugerir que a direção N-S foi uma importante direção de fluxo no passado. Também é possível que, atualmente, a direção N-S oriente fluxos locais, ligando em profundidade condutos $\mathrm{E}-\mathrm{W}$ mais bem desenvolvidos, os quais são os principais transportadores de água em escala regional, antes de alcançar os pontos de descarga para o sistema superficial.

\section{CONCLUSÕES}

Os paleocondutos de dissolução de maior frequência possuem direção $\mathrm{E}-\mathrm{W}$ com mergulho suave para $\mathrm{E}$ e teriam se desenvolvido a partir da interseção entre os planos das fraturas E-W $\left(\theta \geq 45^{\circ}\right)$ e os suaves planos de acamamento.

A concordância entre as direções de fluxo E-W, NE-SW e NW-SE dos traçadores e as direções preferenciais de fraturas, paleocondutos e cavernas aponta que o acamamento juntamente com as fraturas E-W de alto ângulo são as principais estruturas norteadoras do fluxo regional, orientando a água por meio de condutos em direção ao nível de base regional. Ademais, apesar de a direção de cavernas N-S ser relevante em número e desenvolvimento linear, ela não é observada nos fluxos atuais, podendo ter sido uma importante direção de fluxo no passado, bem como estar orientando fluxos locais, mais profundos em conexão com os E-W.

Os resultados desse estudo contribuem para a implantação de uma rede de monitoramento das águas subterrâneas da região, cujo manancial é relevante para o abastecimento das atividades antrópicas, da manutenção do ecossistema cárstico, além de constituir de um recurso estratégico para a RMBH.

\section{AGRADECIMENTOS}

Ao Centro Nacional de Pesquisa e Conservação de Cavernas (CECAV) pelo financiamento das pesquisas do Projeto FUNDEP/GER-
DAU/UFMG No 22.317.

\section{REFERÊNCIAS}

ALKMIM, F.F.; MARTINS-NETO, M.A. A bacia intracratônica do São Francisco: Arcabouço estrutural e cenários evolutivos. In: PINTO, C.P.; MARTINSNETO, M.A. (Eds.). Bacia do São Francisco: Geologia e recursos naturais. Belo Horizonte: SBG, p. 9-30, 2001.

AULER A. Hydrogeological and Hydrochemical Characterization of the Matozinhos-Pedro Leopoldo Karst, Brazil. 1994. 110 f. Msc Thesis, Faculty of the Department of Geography and Geology, Western Kentucky University, Bowling Green, 1994.

AULER, A. Lakes as speleogenetic agent in the karst of Lagoa Santa, Brazil. Cave and Karst Science, v.21, p.105-110, 1995.

AULER, A.S.; PILÓ, L.B. Lagoa Santa Karst: Cradle of Brazilian cave studies. In: VIEIRA, B.C.; SALGADO, A.A.R.; SANTOS, L.J.C. (Eds.) Landscapes and Landforms of Brazil. Dordrecht: Springer, p.183-190, 2015.

BERBERT-BORN, M. Carste de Lagoa Santa, MG - Berço da paleontologia e da espeleologia brasileira. In: SCHOBBENHAUS, C.; CAMPOS, D.A.; QUEIROZ, E.T.; WINGE, M.; BERBERT-BORN, M.L.C. (Eds.) Sítios Geológicos e Paleontológicos do Brasil. 1. ed. Brasília: DNPM/CPRM - Comissão Brasileira de Sítios Geológicos e Paleobiológicos (SIGEP), p. 415-430, v. 1, 2002.

BERBERT-BORN, M.; HORTA, L.S.; DUTRA, G.M. Levantamento Espeleológico. In: APA Carste de Lagoa Santa - Patrimônio Espeleológico, Histórico e Cultural - Volume III. Belo Horizonte: CPRM/IBAMA, 1998, 71p.

DA-GLORIA, P.; NEVES, W.A.; HUBBE, M. (Eds). Archaeological and Paleontological Research in Lagoa Santa: The Quest for the First Americans. Springer: New York, 2017, 420p.

FORD, D.C.; WILLIAMS, P.W. Karst hydrogeology and geomorphology. Rev. ed. John Wiley \& Sons Ltd: Chichester, 2007, 576p.

GALVÃO, P; HALIHAN, T; HIRATA, R. Evaluating karst geotechnical risk in the urbanized area of Sete Lagoas, Minas Gerais, Brazil. Hydrogeology Journal. v. 23 , p. $1499-1513,2015$.

PALMER, A.N. Cave geology. Cave Books: Dayton, 2007, 454p.

PEÑARANDA SALGADO, J.R. Condicionamento estrutural e litológico da porosidade cárstica da formação Sete Lagoas, Município de Sete Lagoas (MG). 2016. Dissertação (Mestrado em Hidrogeologia e Meio Ambiente) Instituto de Geociências, Universidade de São Paulo, São Paulo. 2016.

PESSOA, P.F.P. Hidrogeologia dos Aqüíferos Cársticos Cobertos da Região de Lagoa Santa, MG. 2005. 335 f. Tese de Doutorado (Saneamento, Meio Ambiente e Recursos Hídricos), Escola de Engenharia, Universidade Federal de Minas Gerais, Belo Horizonte. 2005.

RIBEIRO, J.H.; TULLER, M.P.; FILHO, A.D.; PADILHA, A.V.; CÓRDOBA, C.V. Projeto VIDA: mapeamento geológico, região de Sete Lagoas, Pedro Leopoldo, Matozinhos, Lagoa Santa, Vespasiano, Campim Branco, Prudente de Morais, Confins e Funilândia, Minas Gerais - relatório final, escala 1:50.000. 2. ed. Belo Horizonte: CPRM, 2003, 54p.

SHUSTER, E.T.; WHITE, W.B. Seasonal Fluctuations in the Chemistry of Limestones Springs: a Possible Means for Characterizing Carbonate Aquifers. Journal of Hydrology, v. 14, p. 93-128, 1971.

VELÁSQUEZ, L.N.M.; SAMPAIO, J.L.S.; CAMPELLO, M; DUSSIN, T.M.; RODRIGUES, P.C.H.; MINARDI, P.S.P. (Org.) $2^{\circ}$ Relatório Parcial de 04 do Projeto de Adequação e Implantação de uma Rede de Monitoramento de Águas Subterrâneas em Áreas com Cavidades Cársticas da Bacia do Rio São 
Francisco Aplicado à Área Piloto da APA Carste de Lagoa Santa, Minas Gerais. Belo Horizonte, p. 75-85, 2017. (inédito)

VIANA, H.S.; KOHLER, H.C.; TAVARES, V.P. (Org.). APA Carste de Lagoa Santa - Meio Físico - Volume I. Belo Horizonte: IBAMA/CPRM, 1998, 301p.

VIEIRA, L.C.M.; DUSSIN, T.M.; VELÁSQUEZ, L.N.M. Geoquímica e condições paleoambientais de deposição das rochas carbonáticas da Formação Sete
Lagoas na região da Área de Proteção Ambiental Carste de Lagoa Santa, MG. Geochimica Brasiliensis, v.32, n.1, p.1-19, 2018.

WHITE, W.B. Karst hydrology: recent developments and open questions. Engineering Geology, v.65, p.85-105, 2002.

WORTHINGTON, S.H.R. Hydraulic and geological factors influencing conduit flow depths. Caves and Karst Science, v.31, n.3, p.123-134, 2005. 